\title{
PENGARUH RELIGIOUS COMMITMENT DAN ISLAMIC PHYSICAL DAN NON PHYSICAL ATTRIBUTES TERHADAP CUSTOMER LOYALTY DENGAN MEDIASI CUSTOMER SATISFACTION PADA MASYARAKAT BERAGAMA ISLAM YANG BERKUNJUNG KE LUAR NEGERI
}

\author{
Angeline Suwandi \\ Program Studi Magister Manajemen Universitas Tarumanagara \\ angelinesuw@gmail.com \\ Hetty Karunia Tunjungsari \\ Program Studi Magister Manajemen Universitas Tarumanagara
}

Masuk : 06-06-2020, revisi : 26-06-2020 diterima untuk diterbitkan : 26-06-2020

\begin{abstract}
This research was conducted with the aim to examine the effects between the variables of religious commitment and Islamic attributes to customer satisfaction as a mediating variable with customer loyalty. The sample of this study is the Muslim community who have visited abroad and are domiciled in JABODETABEK. Data was collected through a survey using a questionnaire. The respondents obtained were 201 respondents with a purposive sampling technique. The data processing method uses PLS-SEM which is assisted by smartPLS 3.0 software. The results showed that religious commitment had no significant effect on Islamic physical attributes and significant variables on Islamic non-physical attributes and customer satisfaction. The two indicators contained in Islamic physical attributes each have a significant and insignificant role on customer satisfaction, while the Islamic non-physical attribute variable has a significant effect on customer satisfaction. Customer satisfaction may act as a good mediator between religious commitment and Islamic physical attributes on customer loyalty.
\end{abstract}

\begin{abstract}
Abstrak: Penelitian ini bertujuan untuk menguji pengaruh religious commitment dan islamic attributes terhadap customer satisfaction sebagai variabel yang memediasi dengan customer loyalty. Objek penelitian ini adalah masyarakat beragama Islam yang pernah berkunjung keluar negeri dan berdomisili di JABODETABEK. Data dikumpulkan dengan menggunakan kuesioner kepada sebanyak 201 responden dengan menggunakan teknik purposive sampling. Metode analisis data menggunakan PLS-SEM yang dibantu oleh software smartPLS 3.0. Hasil penelitian menunjukkan bahwa religious commitment memiliki pengaruh tidak signifikan terhadap variabel islamic physical attributes dan berpengaruh signifikan terhadap islamic non physical attributes serta customer satisfaction. Dua indikator yang terdapat dalam islamic physical attributes masing-masing berperan signifikan dan tidak signifikan terhadap customer satisfaction, sedangkan variabel islamic non physical attributes berpengaruh signifikan terhadap customer satisfaction. Customer satisfaction dapat berperan sebagai mediator yang baik antara religious commitment dan islamic physical attributes terhadap customer loyalty.
\end{abstract}

Keywords: Religious Commitment, Islamic Physical Attributes, Islamic Non Physical Attributes, Customer Satisfaction, Customer Loyalty

\section{PENDAHULUAN}

Permasalahan utama yang biasa dilalui oleh umat muslim saat berkunjung ke luar negeri adalah keterbatasan dalam menemukan restoran yang menjual makanan halal di negara tertentu. Istilah Halal dalam buku "The Lawful and the Prohibited in Islam" yang ditulis oleh 
Sheikh Yusuf al-Qaradawi (Battour, 2015) berarti: “Apa yang diizinkan, sehubungan dengan yang tidak ada batasan, dan perbuatan yang diizinkan pemberi hukum, Allah, diizinkan."

Dalam Zailani et al. (2015) menyebutkan bahwa dalam Quran memerintahkan umat Islam untuk mengkonsumsi makanan halal dan melarang yang haram. Konsumen Muslim sensitif terhadap produk dan layanan yang ditawarkan di pasar dan ingin diyakinkan bahwa makanan apapun yang mereka makan akan sesuai dengan prinsip-prinsip Islam (Zailani et al., 2015). Menurut Zakaria et al. (2017), halal merupakan salah satu atribut produk yang tidak dapat di verifikasi oleh konsumen individu pada saat pembelian dan bahkan setelah mengkonsumsi produk seperti daging.

\section{TELAAH KEPUSTAKAAN \\ Muslim Customer Perceived Value (MCPV)}

Dalam Eid dan El-Gohary (2015), konsep MCPV terdiri dari dua atribut utama yaitu atribut nilai tradisional (termasuk nilai atau kualitas, nilai uang atau harga, nilai emosional, dan nilai sosial) dan atribut nilai islami (termasuk dimensi atribut fisik islam dan atribut non fisik islam). Atribut fisik Islam meliputi ketersediaan fasilitas ibadah meliputi mukena, alquran serta ketersediaan toilet sesuai dengan syariah Islam, penampilan karyawan sesuai dengan norma Islam, ketersediaan makanan dan minuman halal. Atribut nonfisik Islam terdiri dari ketersediaan layanan yang terpisah, ketersediaan produk yang sesuai dengan syariah Islam, ketersediaan musik Islami dan sebagainya. Dalam Usman (2019), Atribut fisik islam dibagi menjadi beberapa dimensi yaitu halal labeled products dan islamic atmosphere dan dimensi dari atribut non fisik islam yaitu islamic standard of operating procedures.

\section{Religious Commitment}

Borzooei dan Asgari (2014) mendefinisikan bahwa komitmen keagamaan berperan penting karena mempengaruhi perilaku konsumen dalam kaitannya dengan niat dan kesetiaan terhadap merek tertentu di pasar. Sejauh mana muslim berkomitmen pada Islam dan tingkat religiusitas mereka juga dapat mempengaruhi sikap Muslim dalam mengkonsumsi makanan halal. Konsumsi makanan halal adalah resep diet alami dan tergantung pada tingkat komitmen keagamaan antar individu (Verbeke et al. 2008 dalam Iranmanesh et al. 2018)

\section{Customer Satisfaction}

Menurut Oliver (1997) dalam Usman (2019) mendefinisikan bahwa kepuasan sebagai respon pelanggan dalam bentuk suatu penilaian suatu produk atau layanan itu sendiri adalah kebutuhan yang terpenuhi. Zeithaml dan Bitner (2003) dalam Usman (2019) juga menjabarkan definisi kepuasan menurut Oliver adalah evaluasi suatu produk atau layanan telah memenuhi mereka kebutuhan dan harapan. Sebaliknya, pelanggan akan merasa tidak puas jika kepuasan mengandung ukuran kognitif seperti harapan dan ukuran afektif seperti kesenangan (Fraering dan Minor 2013 dalam Jaharuddin et al. 2019)

\section{Customer Loyalty}

Menurut Anderson dan Srinivasan (2003) dalam Hanzaee dan Esmaeilpour (2017) loyalitas adalah proses pembelian perilaku yang bias yang dihasilkan dari proses psikologis. Pelanggan yang loyal memiliki komitmen yang kuat untuk merek karena mereka percaya bahwa itu lebih memuaskan daripada alternatif (Hanzaee dan Esmaeilpour, 2017).

\section{HIPOTESIS PENELITIAN}

Berdasarkan latar belakang penelitian dan tujuan teoritis yang dikemukakan, maka hipotesis yang dibuat:

H1: Komitmen keagamaan (Religious Commitment) berpengaruh positif dan signifikan terhadap kepuasan pelanggan (Customer satisfaction)

H2: Atribut fisik Islam (Islamic Physical Attributes) meliputi ketersediaan produk dan jasa Muslim, produk yang berlabel halal, dan suasana islami berpengaruh positif dan signifikan terhadap kepuasan pelanggan (Customer satisfaction). 
H3: Atribut non fisik Islam (Islamic Non Physical Attributes) meliputi penerapan nilai-nilai Islam, nilai-nilai humanistik dan prosedur operasional Islam berpengaruh positif dan signifikan terhadap kepuasan pelanggan (Customer satisfaction).

H4: Kepuasan pelanggan (Customer Satisfaction) berpengaruh positif dan signifikan terhadap kesetiaan pelanggan (Customer Loyalty).

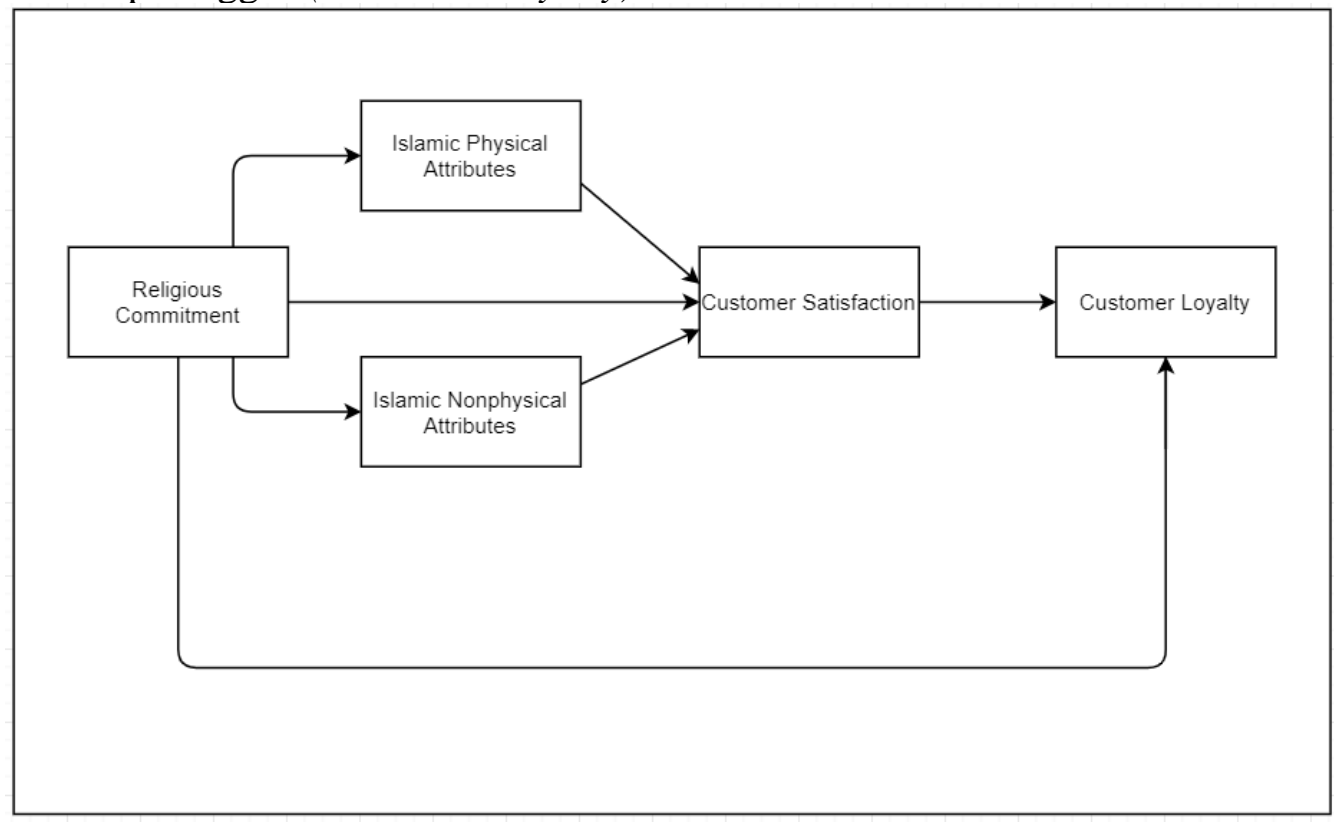

Gambar 1

Kerangka Pemikiran

\section{METODE PENELITIAN}

Dalam penelitian ini, metode analisis yang digunakan dalam mengolah data responden adalah Partial Least Square (PLS). Menurut Ghozali (2016:417), metode PLS dijelaskan sebagai model persamaan struktural berbasis variance mampu menggambarkan variabel laten (tak terukur langsung) dan diukur menggunakan indikator-indikator (Variabel Manifest). Penelitian ini menggunakan data dari hasil jawaban responden yang diperoleh melalui pembagian kuesioner. Kuesioner tersebut dibuat secara online dengan bantuan google-form dan disebarkan melalui media sosial. Kuesioner ini melibatkan sebanyak 201 responden secara keseluruhan yang berfokus pada responden Muslim di wilayah JABODETABEK. Teknik pemilihan sampel menggunakan purposive sampling. Pengukuran objek penelitian diukur dengan menggunakan skala likert 5 poin, 1 menunjukkan "sangat tidak setuju" dan 5 menunjukkan "sangat setuju".

Dalam Ghozali \& Latan (2015), analisis PLS-SEM biasanya terdiri dari dua sub model yaitu model pengukuran (measurement model) atau sering disebut dengan outer model dan model struktural (structural model) atau sering disebut dengan inner model. Penelitian ini menggunakan analisis seperti yang diungkapkan oleh Ghozali dan Latan (2015).

\section{HASIL DAN PEMBAHASAN}

Nilai signifikansi model dapat dilihat dari nilai T-statistic yang harus $>1,96$ untuk model t-statistics dengan signifikansi level 5\%. Berdasarkan hasil bootstrapping yang disajikan pada tabel 1 dapat dilihat bahwa pada variabel religious commitment terbukti berpengaruh secara positif dan tidak signifikan terhadap variabel customer loyalty penelitian ini didukung oleh penelitian Abror et. al (2018), variabel religious commitment terbukti berpengaruh secara positif dan tidak signifikan terhadap variabel halal labeled products penelitian ini didukung oleh penelitian dari Rahayu (2019), variabel religious commitment terbukti berpengaruh secara negatif dan signifikan terhadap variabel islamic atmosphere penelitian ini didukung oleh 
penelitian dari Eid \& Gohary (2015), variabel religious commitment terbukti berpengaruh secara negatif dan signifikan terhadap variabel islamic standard of operating penelitian ini didukung oleh penelitian dari Putra et.al (2016), variabel religious commitment terbukti berpengaruh secara positif dan signifikan terhadap variabel customer satisfaction penelitian ini didukung oleh penelitian dari Yaakop (2017), variabel halal labeled products terbukti berpengaruh secara positif dan signifikan terhadap variabel customer satisfaction penelitian ini didukung oleh penelitian dari Rahman (2014), variabel islamic atmosphere terbukti berpengaruh secara positif dan tidak signifikan terhadap variabel customer satisfaction penelitian ini didukung oleh penelitian dari Putri et. al (2014), variabel islamic Atmosphere terbukti berpengaruh secara negatif dan signifikan terhadap variabel customer satisfaction penelitian ini didukung oleh penelitian dari Eid \& Gohary (2015), variabel customer satisfaction terbukti berpengaruh secara positif dan signifikan terhadap variabel customer loyalty penelitian ini didukung oleh Rahayu (2016).

\section{Tabel 1}

\section{Hasil Pengujian Hipotesis}

\begin{tabular}{|c|c|c|c|}
\hline & $\begin{array}{c}\text { Original } \\
\text { Sample (O) }\end{array}$ & $\begin{array}{l}\text { T Statistics } \\
(\mid \text { O/STDEV } \mid)\end{array}$ & $P$ Values \\
\hline $\begin{array}{l}\text { Customer Satisfaction -> Customer } \\
\text { Loyalty }\end{array}$ & 0.580 & 13.306 & 0.000 \\
\hline $\begin{array}{l}\text { Halal Labeled Products } \rightarrow \text { Customer } \\
\text { Satisfaction }\end{array}$ & 0.145 & 2.190 & 0.029 \\
\hline $\begin{array}{l}\text { Islamic Atmosphere } \rightarrow \text { Customer } \\
\text { Satisfaction }\end{array}$ & 0.061 & 0.806 & 0.421 \\
\hline $\begin{array}{l}\text { Islamic Standard of Operating } \\
\text { Procedures_- }>\text { Customer } \\
\text { Satisfaction }\end{array}$ & -0.122 & 1.685 & 0.093 \\
\hline $\begin{array}{l}\text { Religious Commitment } \rightarrow \text { Customer } \\
\text { Loyalty }\end{array}$ & 0.105 & 1.649 & 0.100 \\
\hline $\begin{array}{l}\text { Religious Commitment } \rightarrow \text { Customer } \\
\text { Satisfaction }\end{array}$ & 0.219 & 2.700 & 0.007 \\
\hline $\begin{array}{l}\text { Religious Commitment } \rightarrow \text { Halal } \\
\text { Labeled Products }\end{array}$ & 0.100 & 1.433 & 0.153 \\
\hline $\begin{array}{l}\text { Religious Commitment } \rightarrow \text { Islamic } \\
\text { Atmosphere }\end{array}$ & -0.175 & 2.514 & 0.012 \\
\hline $\begin{array}{l}\text { Religious Commitment } \rightarrow \text { Islamic } \\
\text { Standard of Operating Procedures_ }\end{array}$ & -0.199 & 3.052 & 0.002 \\
\hline
\end{tabular}

Dari hasil analisis mediasi yang terdapat pada Tabel 2, dapat disimpulkan bahwa variabel mediasi customer satisfaction berhasil memediasi variabel halal labeled products dan religious commitment terhadap customer loyalty. Mediasi yang dihasilkan oleh variabel customer satisfaction terhadap kedua variabel tersebut adalah partial mediation.

Tabel 2

Hasil Analisis Mediasi

\begin{tabular}{|c|c|c|c|c|}
\hline & $\begin{array}{c}\text { Original } \\
\text { Sample (O) }\end{array}$ & $\begin{array}{l}\text { T Statistics } \\
\text { (|O/STDEV|) }\end{array}$ & P Values & Keterangan \\
\hline $\begin{array}{l}\text { Halal Labeled Products -> } \\
\text { Customer Satisfaction -> } \\
\text { Customer Loyalty }\end{array}$ & 0.084 & 2.158 & 0.031 & Signifikan \\
\hline $\begin{array}{l}\text { Islamic Atmosphere -> } \\
\text { Customer Satisfaction -> } \\
\text { Customer Loyalty }\end{array}$ & 0.036 & 0.798 & 0.425 & Tidak Signifikan \\
\hline $\begin{array}{l}\text { Islamic Standard of Opera } \\
\text { Procedures_-> Customer } \\
\text { Satisfaction } \rightarrow \text { Customer } \\
\text { Loyalty }\end{array}$ & -0.071 & 1.661 & 0.097 & Tidak signifikan \\
\hline $\begin{array}{l}\text { Religious Commitment -> } \\
\text { Customer Satisfaction -> } \\
\text { Customer Loyalty }\end{array}$ & 0.127 & 2.757 & 0.006 & Signifikan \\
\hline
\end{tabular}




\section{KESIMPULAN}

Berdasarkan hasil analisis tersebut, maka dapat disimpulkan (1) Religious commitment berpengaruh secara positif dan tidak signifikan terhadap customer loyalty, dan halal labeled products, (2) Religious commitment berpengaruh secara negatif dan signifikan terhadap islamic atmosphere, dan islamic standard of operating, (3) Religious commitment berpengaruh secara positif dan signifikan terhadap customer satisfaction, (4) Halal labeled products berpengaruh secara positif dan signifikan terhadap customer satisfaction, (5)Islamic atmosphere berpengaruh secara positif dan tidak signifikan terhadap customer satisfaction, (6) Islamic standard of operations berpengaruh secara negatif dan signifikan terhadap customer satisfaction, (7)Customer satisfaction berpengaruh secara positif dan signifikan terhadap customer loyalty.

\section{DAFTAR PUSTAKA}

Abu-Alhaija, A.S., Raja Yusof, R.N., Hashim, H., \& Jaharuddin, N. (2019). The influence of religious orientation on viewers' loyalty towards satellite TV channels: The case of Muslim viewers. Journal of Islamic Marketing, 10(4), 1196-1218.

Battour, M., \& Ismail, M. N. (2015). Halal tourism: Concepts, practises, challenges and future. Tourism Management Perspectives.

Borzooei, M., \& Asgari, M. (2014). The effect of religious commitment on halal brand relationship and purchase intention. The International Journal's Research Journal of Economics \& Business Studies, 3(4), 14-19.

Eid, R., \& El-Gohary, H. (2015). The role of islamic religiosity on the relationship between perceived value and tourist satisfaction. Journal of Tourism Management, 46, 477-488

Setiawan, F., Idris, \& Abror. (2018). The relationship between religiosity, service quality, customer satisfaction and customer loyalty. Advances in Economics, Business and Management Research, 64.

Ghozali, I., \& Latan, H. (2015). Partial Least Squares Konsep, Teknik, dan Aplikasi Menggunakan Program SmartPLS 3.0 Untuk Penelitian Empiris ( $2^{\text {nd }}$ ed.). Semarang, ID: Badan Penerbit Undip.

Heidarzadeh Hanzaee, K., \& Esmaeilpour, F. (2017). Effect of restaurant reward programs on customers' loyalty: evidence from Iran. Journal of Islamic Marketing, 8(1), 140-155.

Parvin Hosseini, S. M., Mirzaei, M., \& Iranmanesh, M. (2019). Determinants of Muslims' willingness to pay for halal certified food: Does religious commitment act as a moderator in the relationships? Journal of Islamic Marketing. https://doi.org/10.1108/JIMA-022018-0043

Sobari, N., Kurniati, A., \& Usman, H. (2019). The influence of Islamic attributes and religious commitments toward halal wellness services customer satisfaction and loyalty. Journal of Islamic Marketing. https://doi.org/10.1108/JIMA-11-2018-0221

Zailani, S., Kanapathy, K., Iranmanesh, M., \& Tieman, M. (2015). Drivers of halal orientation strategy among halal food firms. British Food Journal, 117(8), 2143-2160.

Zakaria, Z., Abdul Majid, M. D., Ahmad, Jusoh, \& Zakaria, N. Z. (2017). Influence of Halal Certification on Customers' Purchase Intention. Journal of Fundamental and Applied Sciences, $9(5 \mathrm{~S}), 772-787$ 